\title{
Planetary limits, social needs and economics for the Anthropocene
}

Written by: Joshua Farley, Professor, Community Development and Applied Economics, and Fellow, Gund Institute for Ecological Economics, University of Vermont

Last update: 17 November 2015

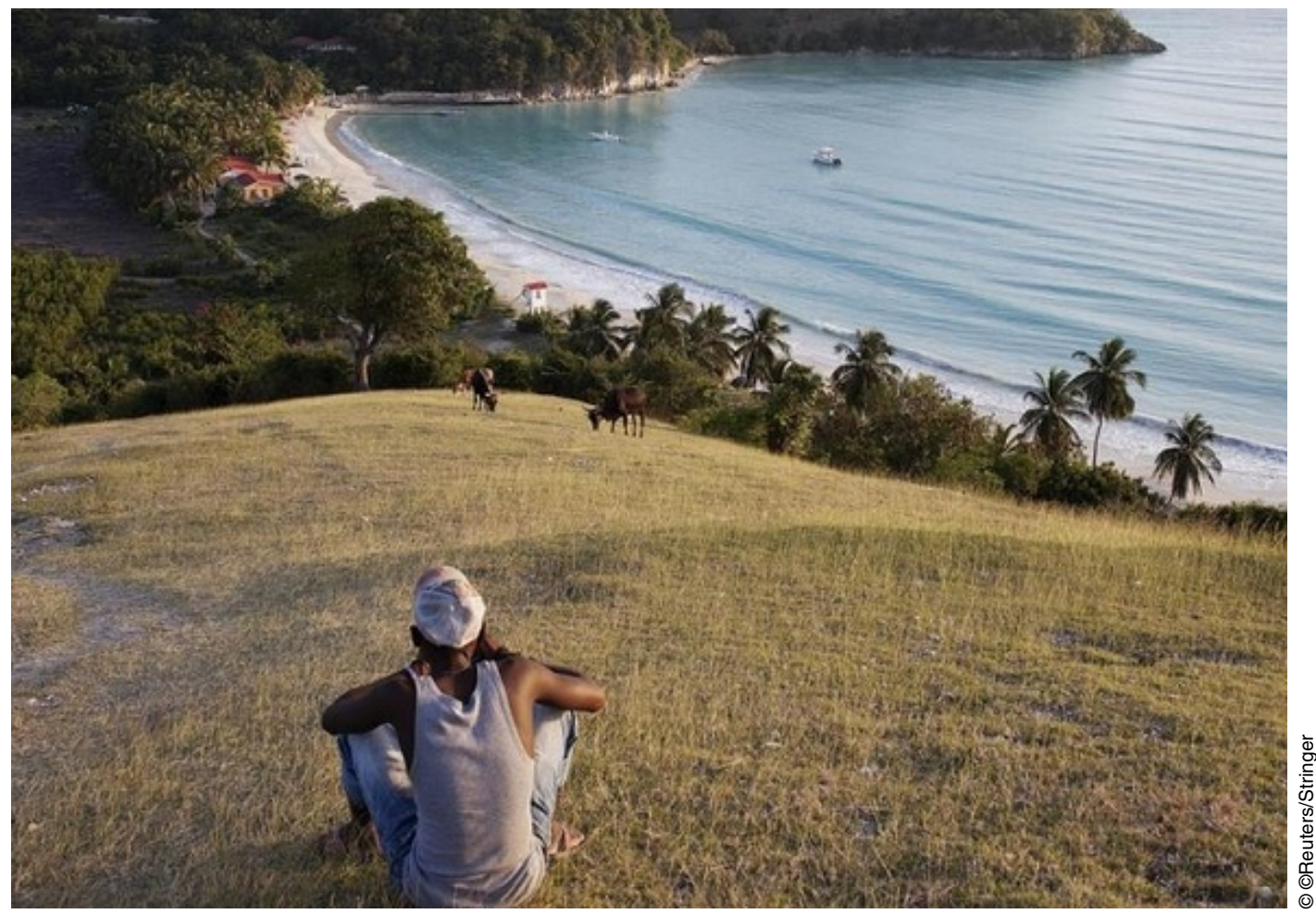

The human economy is a physical system embedded in society, which itself is embedded in a finite global ecosystem. The primary goal of the economy should be to meet basic human and social needs, now and in the future, without degrading the global ecosystem services upon which all life depends. How can this be done?

All economic activity must obey the laws of physics and ecology. It is impossible to create something from nothing: every physical thing an economy produces is the transformation of raw materials provided by our finite planet. All economic production also requires energy, over $80 \%$ of which is provided by finite fossil 
fuels. Burning them generates waste, greenhouse gases and other pollutants. Moreover, all economic products wear out, break down or fall apart.

It is also impossible to create nothing out of something: the economy transforms raw materials and energy into economic products and returns them to the ecosystem as waste. A law of ecology is that everything is connected to everything else, so when we transform raw materials and energy into economic products and waste, we inevitably degrade the ecosystems upon which all life depends. Furthermore, ecosystems are subject to thresholds beyond which a small change in human activity can cause catastrophic and potentially irreversible ecological outcomes. We cannot accurately predict where those thresholds lie, or what lies beyond them. But we do know that to maintain healthy ecosystems while ensuring that people's basic needs are met, those thresholds must be respected.

The trouble is, current rates of resource extraction and waste emissions are changing ecological functions and geochemical processes so rapidly that many scientists claim we have entered a new geological epoch-the Anthropocene-in which we run growing risk of crossing these ecological thresholds (see for instance, Steffen et al., 2015). Meanwhile, nearly a billion people are still chronically malnourished. We need a new economic system capable of meeting basic needs without exceeding planetary boundaries.

Can the market economy meet this challenge? The strengths of markets are that, under certain conditions, they maximise the monetary value of production and consumption as determined by the subjective preferences and free choices of individuals, and incentivise innovation. Unfortunately, for the challenge of remaining within planetary boundaries, markets are unlikely to achieve these outcomes, while for the challenge of meeting basic needs, their desirability is questionable. These claims require elaboration.

The most obvious problem is that many essential ecological functions, such as climate stability, cannot be owned. Markets therefore ignore their values, treating them as "externalities", and will produce long past the point where the ecological costs of additional output exceed the market benefits. Individuals cannot choose how much to consume. For this reason, decisions to bolster ecosystem resilience must be collective.

Another serious problem with markets is that they weight preferences by purchasing power, favouring the whims of the rich over the needs of the poor. During the food crises of 2007-08 and 2011-12, the prices of staple grains doubled in response to small decreases in supply. In countries consuming over 3500 calories per person per day, where the marginal utility of eating more food is zero or negative, our research found that consumption remained stable and people continued to throw away some $30-40 \%$ of the food they purchased. In countries where people were already consuming too little to meet basic needs, they cut their consumption even further, exacerbating already high levels of malnutrition and 
increasing political unrest. If our goal is to maximise monetary value, then it is more efficient to allocate a loaf of bread to a wealthy, possibly overfed Western consumer who throws a third of it away, rather than to a destitute African woman desperate to feed her starving children simply because the former can pay more. Ironically, a small reduction in the supply of essential resources causes their price, and hence the revenue they generate, to skyrocket, thus boosting GDP.

This perverse outcome raises serious alarms about internalising ecological costs into market prices as a solution to planetary boundaries-it would force the greatest sacrifices from those who contributed the least to causing the problems. If we are to use a pricing policy, prices should reflect both ecological and humanitarian costs: an appropriate price signal should make it vastly more expensive to buy fossil fuels for a private jet than for the satisfaction of basic needs such as food, water and shelter.

Markets may also be poorly designed for stimulating appropriate innovations at lowest cost. The profit motive provides little incentive for innovations that meet the needs of the poor, who have negligible purchasing power. In a classic example, drug companies halted production of the drug called eflornithine to cure African sleeping sickness because it made no profit, but continued to market the same compound in wealthy countries to slow the growth of unwanted facial hair.

Market incentives for innovation also require patents, which raise the cost of using existing information and slow the rate of scientific advance, as several researchers have shown. This is hardly the way to address pressing climate change. Furthermore, once a green technology has been developed, its social value is maximised when it is made freely available to all. If society developed clean, dependable and inexpensive solar energy, it would be counterproductive to limit use to those who could pay monopoly prices, while leaving others to burn coal. It is true that patents last only 20 years and then become part of the public domain, but can we afford to delay the widespread adoption of green technologies for that long?

Competitive markets worked well for a fossil fuel economy far from planetary boundaries. Now however, the physical boundaries of the planet compel us to make a transition to a zero-carbon, solar energy future. Countries need not compete for solar energy, since one country's use leaves no less for others and technological innovations for capturing solar energy improve through sharing. The maximisation of monetary value largely excludes the poor, and unbridled economic growth exacerbates climate change. This is why governments must act together, which is what the UN climate change summit in Paris is about.

New approaches are needed. One would be for the richest countries to fund a global research effort into green technologies-especially alternative energy-with results made freely available to all, on the condition that any improvements are also open access. Open source software and the Internet have used this approach 
to unleash innovations. This "sharing economy" approach could stimulate the conditions of trust and reciprocity required to develop co-operative solutions to other global problems. Another would be to ensure that basic needs are met before selling essential resources to the highest bidder. We cannot simply assume that markets are always best.

An economics for the Anthropocene must be grounded in science but guided by moral values. Together, we must first decide on the socially, morally and psychologically desirable ends of economic activity-perhaps using the UN's Sustainable Development Goals as a start-and then assess how to achieve them. Only then can we determine what economic institutions will meet our goals.

@OECD Observer No 304, November 2015

\section{References}

AAH (2009), Feeding Hunger and Insecurity: The Global Food Price Crisis. A summary of Action Against Hunger research in Ethiopia, Sierra Leone, Central African Republic and Liberia, Briefing Paper, January. http:// www.actioncontrelafaim.org/sites/default/files/publications/fichiers/ feedinghungerandinsecuritybrieflq.pdf

Benkler, Yoshai (2004), "Commons-Based Strategies and the Problems of Patents", Science, Volume 305. https://science.sciencemag.org/ content/305/5687/1110

Berazneva, Julia, and David R. Lee (2013), “Explaining the African food riots of 2007-2008: An empirical analysis", Food Policy, Volume 39. https:// linkinghub.elsevier.com/retrieve/pii/S0306919212001327

FAO (2013), Statistical Yearbook 2013: World food and agriculture, FAO, Rome. http://www.fao.org/3/i3107e/i3107e00.htm

FAO (2009), The State of Food Insecurity in the World, FAO, Rome. http:// www.fao.org/3/i0876e/i0876e00.htm

Farley, Joshua, Abdon Schmitt Filho, Matthew Burke, and Marigo Farr (2014), "Extending market allocation to ecosystem services: Moral and practical implications on a full and unequal planet", Ecological Economics, Volume 117. https://www.sciencedirect.com/science/article/pii/S0921800914002018? via\%3Dihub

Farley, Joshua, and Skyler Perkins (2013), "Economics of Information in a Green Economy", Building a Green Economy, Michigan State University Press, East Lansing, Michigan. http://www.uvm.edu/ jfarley/publications/DRAFTThe\%20economics\%20of\%20information\%20in\%20a\%20green\%20economy.pdf

Foley, Jonathan A., Navin Ramankutty, Kate A. Brauman, Emily S. Cassidy, James S. Gerber, Matt Johnston, Nathaniel D. Mueller, Christine O'Connell, Deepak K. Ray, Paul C. West, Christian Balzer, Elena M. Bennett, Stephen R. Carpenter, Jason Hill, Chad Monfreda, Stephen Polasky, Johan Rockstrom, John Sheehan, Stefan Siebert, David Tilman, and David P. M. Zaks (2011), "Solutions for a cultivated planet”, Nature, Volume 478. https://www.nature.com/articles/ nature10452 
Godfray, H. Charles J., John R. Beddington, Ian R. Crute, Lawrence Haddad, David Lawrence, James F. Muir, Jules Pretty, Sherman Robinson, Sandy M. Thomas, and Camilla Toulmin (2010, "Food security: The Challenge of Feeding 9 Billion People”, Science, Volume 327. http://dx.doi.org/10.1126/science.1185383

Gustavsson, Jenny, Christel Cederberg, Ulf Sonesson, Robert van Otterdijk, and Alexandre Meybeck (2011), Global Food Losses and Food Waste: Extent, Causes and Prevention, FAO, Rome. http://www.fao.org/ag/ags/ags-division/ publications/publication/en/c/74045/

Heller, Michael, and Rebecca Eisenberg (1998), "Can Patents Deter Innovation? The Anticommons in Biomedical Research", Science, Volume 280. https:// science.sciencemag.org/content/280/5364/698

IEA (2014), 2014 Key World Energy Statistics, OECD Publishing. https:// www.iea.org/publications/freepublications/publication/keyworld2014.pdf

Lei, Zhen, Rakhi Juneja, and Brian D. Wright (2009), "Patents versus patenting: implications of intellectual property protection for biological research", Nature Biotechnology, Volume 27. https://www.nature.com/articles/nbt0109-36

Murray, Fiona, and Scott Stern (2006), "When Ideas Are Not Free: The Impact of Patents on Scientific Research", Innovation Policy and the Economy. http:// www.nber.org/chapters/c0033.pdf

Sampat, Bhaven N. (2006), "Patenting and US academic research in the 20th century: The world before and after Bayh-Dole", Research Policy, Volume 35. https://www.sciencedirect.com/science/article/pii/S0048733306000692

Steffen, Will, Jacques Grinevald, Paul Crutzen, and John McNeill (2011), “The Anthropocene: Conceptual and historical perspectives", Philosophical Transactions of the Royal Society A: Mathematical, Physical and Engineering Sciences, Volume 369. https://royalsocietypublishing.org/doi/10.1098/ rsta.2010.0327

Steffen, Will, Katherine Richardson, Johan Rockström, Sarah E. Cornell, Ingo Fetzer, Elena M. Bennett, Reinette Biggs, Stephen R. Carpenter, Wim de Vries, Cynthia A. de Wit, Carl Folke, Dieter Gerten, Jens Heinke, Georgina M. Mace, Linn M. Persson, Veerabhadran Ramanathan, Belinda Reyers, and Sverker Sörlin (2015), "Planetary boundaries: Guiding human development on a changing planet", Science, Volume 347. http://www.sciencemag.org/ content/347/6223/1259855 